\title{
Article
}

\author{
Doi 10.5943/sif/4/1/15
}

\section{Entomopathogenic fungi isolated from Yukon soil against unfed larvae of the winter tick, Dermacentor albipictus}

\section{Dobrotka $\mathrm{CJ}^{1}$, Krieger $\mathbf{M}^{2}$, Oakley $\mathbf{M}^{3}$, Trotter $\mathrm{J}^{3}$, Rodell $\mathbf{B M}^{1}$, Stein $\mathbf{K L}^{1}$, Klever $\mathrm{LA}^{\mathbf{1}}$, Fisher $\mathrm{KA}^{\mathbf{1}}$ and Yoder $\mathrm{JA}^{\mathbf{1}}$}

${ }^{1}$ Department of Biology, Wittenberg University, Springfield, OH, 45501, USA

${ }^{2}$ Champagne and Aishihik First Nations, Haines Junction, YT, Y0B 1L0, CAN

${ }^{3}$ Oakley Veterinary Services, Haines, AK, 99827, USA

Dobrotka CJ, Krieger M, Oakley M, Trotter, J, Rodell BM, Stein KL, Klever LA, Fisher KA, Yoder JA 2019 - Entomopathogenic fungi isolated from Yukon soil against unfed larvae of the winter tick, Dermacentor albipictus. Studies in Fungi 4(1), 123-134, Doi 10.5943/sif/4/1/15

\begin{abstract}
Fungal composition of Yukon soil samples consisted of 29 soil saprobes common to acidified forest, subarctic habitats. All of the fungi identified are psychrotrophs, capable of growth at both $4^{\circ} \mathrm{C}$ and $20^{\circ} \mathrm{C}$. Of these, a total of 17 fungi were found to be entomopathogenic by winter tick (Dermacentor albipictus) larval bioassays: Aspergillus flavus, Beauveria, namely B. bassiana, Mucor, Paecilomyces yielded $>\sim 70 \%$ larval mortality and the remainder, mostly Mortierella and Penicillium, averaged $\sim 40 \%$ larval mortality. Sites where elk (Cervus elaphus canadensis) are observed had an overall greater quantity, and diversity of entomopathogenic soil fungi than sites where elk are not observed. Greater diversity of fungi at elk-inhabited sites is likely a product of warmer soil microclimate (hillsides where elk are seen, lose snow earlier than other areas), animal presence, and increased nutrient enrichment. We conclude that Yukon soils contain fungi that naturally regulate populations of $D$. albipictus. All fungi are archived at the Wittenberg University Fungus Collection, Springfield, OH, USA.
\end{abstract}

Key words - Biological control - mycoflora - moose tick - elk tick - horse tick - Canada - Alaska

\section{Introduction}

Fungi critically limit the availability of ticks that infest hosts by functioning as natural regulators mainly in association with soil, in addition to functioning as saprobic agents of decay (Tuininga et al. 2009, Greengarten et al. 2011, Yoder et al. 2018). The most virulent fungi for biocontrol of ticks come from the tick's natural environment (Fernandes et al. 2012). Upon exposure to fungal spores, the spores stick to the surface of the tick, germinate, and grow into hyphae that penetrate and gain access to the tick insides. Excessive dehydration occurs as a pathogenic consequence of the infection, killing the tick in the process. The end result is a dried carcass, tick "mummy" covered with a whitish fungal mycelium (Yoder et al. 2017). Many fungi isolated from soil have been used commercially as biological control agents (Fernandes et al. 2012). Few, if any, entomopathogenic fungi to ticks have been isolated from Yukon. This paper seeks to make a contribution to this area by examining twenty Yukon soil samples for the presence of entomopathogenic fungi that may be working against the winter tick, Dermacentor albipictus. In the life history of $D$. albipictus (one-host tick), the larva is only active, ground-dwelling stage, and the larva is also the only stage that quests and infests new hosts (Samuel 2004). 
In Yukon, D. albipictus is primarily a parasite of elk, Cervus elaphus canadensis and mule deer Odocoileus hemionus (Leo et al. 2014; pers. observ. of authors, J. Trotter \& M. Oakley). A potential decline in moose (Alces alces) population that results from blood feeding by numerous $D$. albipictus ticks ("ghost moose"; Samuel 2004) is a major concern in Yukon and surrounding areas. There is a particular concern with the possible spread of D. albipictus into Alaska. D. albipictus has been observed on mule deer in Yukon and mule deer regularly migrate into Interior Alaska from Yukon (pers. comm. K. Beckmen, Alaska Department of Fish and Game, Fairbanks AK), but this tick apparently has not yet established in Alaska (Durden et al. 2016).

To clarify the present situation, D. albipictus are not known to be found or established in SW Yukon in moose. D. albipictus are thought to be a new parasite brought to Yukon on elk introduced from Alberta. Elk released as part of a reintroduction program in the 1980s were observed to have D. albipictus on them when released, but it was thought at the time the ticks could not survive the cold climate. We now know that $D$. albipictus can handle low temperature stress and is suitable for fall (activity/questing) - summer (dormancy) survival in Alaska (Zarnke et al. 1990, Holmes et al. 2018). Whether elk gave D. albipictus to deer, or these ticks came with deer is not known. Assumptions are D. albipictus are already in E Yukon/N Alberta on deer, and maybe those migrating deer have brought small numbers of ticks for years. But, D. albipictus ticks on deer in SW Yukon (our study area) have not been noticed until recently (pers. observ. of author, M. Oakley \& S. Kutz, University of Calgary, Calgary, AB).

Soils from Yukon have not been screened for tick-fungal pathogens. The purpose of this study was to isolate fungi from Yukon soil and determine whether any of these fungal isolates may be pathogenic to $D$. albipictus larvae, with the goals of: 1 . to better understand population dynamics and spread of $D$. albipictus by examining the efficacy of Yukon soils as a natural regulator of tick larvae, and 2. to enhance biological control programs of D. albipictus for new geographic applications that would depend on strains of entomopathogenic fungi being low temperatureadapted (Robinson 2001, Timling \& Taylor 2012).

\section{Materials \& Methods}

\section{Soil collection}

Twenty soil habitats were sampled from SW Yukon (60 $\mathrm{N} 45-51^{\prime} 135-137^{\circ} \mathrm{W}$ 00-58') in October 2018 (map is shown in Table 1). We will collect the April to October soil samples in the future, as the egg and larvae of $D$. albipictus are still in the soil during this time. Temperatures ranged -1 to $3^{\circ} \mathrm{C}$ during this time of collection. Author J. Trotter has the GPS coordinates (60CSX using WGS 84; Garmin, Olathe, KS). Soil samples were numbered in the field, and these numbers have been retained for cataloging and reference purposes. Each soil sample was taken from the active layer 8-10 cm deep into the topsoil and placed into individual Whirl-Pak bags (Nasco, Salida, CA) and kept at $4^{\circ} \mathrm{C}$. Soil samples were used for fungus analysis 3-4 days after collection. For analysis, soil samples were weighed with a microbalance (Ventron Co., Cerritos, CA). The pH of soil samples was measured following Kalra's (1995) technique. Briefly, 20 g soil was mixed with $40 \mathrm{~mL}$ deionized, double distilled (DI) water, stirred periodically for $30 \mathrm{~min}$, and the $\mathrm{pH}$ was measured with a pH meter (Oakton, Vernon Hills, IL). Measurements were taken at $1 \mathrm{~h}, 2 \mathrm{~h}$, and $3 \mathrm{~h}$, and averaged (the mean $\pm \mathrm{SE}$ ).

For soil samples 1-4, the four locations were spaced 3-5 km apart and are from areas that elk are unlikely to be found and have not been observed.

Soil samples 5-20 are from eight separate locations spaced 1-2 km apart. A pair of samples was taken at each individual location. Samples 5-20 are from areas that elk are known to frequent at all times of the year, so there is a reasonable probability that ticks have been present on those sites. No elk were seen while soil sampling; however, fresh sign was observed at sites of samples 5-20, and elk bugling was heard at two locations as the rut is in full swing during this time in October. The elk prefer a sunny slope in spring, and the elk return to these same spots every autumn (time of 
soil collection in this study). These sites where elk go are on sunny, south facing hillsides, and these areas are snow-free a month or more before other areas.

\section{Experimental materials}

All materials were purchased sterile from the manufacturer (Fisher) or sterilized by autoclave, flame, or 95\% ethanol. Experimental work was carried out wearing gloves and masks (Microlex Co., Reno, NV), in a daily-sterilized vertical laminar flow hood (Cole-Palmer, Vernon Hills, IL). Culture work was done in disposable 100 x $15 \mathrm{~mm}$ Petri plates. The agar growth medium was Potato Dextrose Agar (PDA) + 0.05\% chloramphenicol, adjusted to pH 5.5 with lactic acid (Fisher Scientific, Pittsburgh, PA) to match soil condition. Plating on Sabouraud Dextrose Agar (SDA) was conducted in parallel. Incubation conditions were $4 \pm 0.5^{\circ} \mathrm{C}$ and $20 \pm 0.5^{\circ} \mathrm{C}$, darkness (programmable incubator; Fisher) in confirmation with standard practice for cold-associated, mildly acidic soils (Bergero et al. 1999, Ali et al. 2013). We recognize that not all fungi from soil samples may be cultured by our methods; however, these methods are standard for this kind of soil fungus investigation.

\section{Determination of soil fungus quantity}

Methods for soil analysis followed soil plate dilution method (Tuininga et al. 2009, Suleiman et al. 2013, Cafarchia et al. 2015). Enumeration of soil fungi was carried out using $1 \mathrm{~g}$ soil (expressed as dry mass) diluted in DI water, mixing with a vortex (Scientific Industries, Bohemia, $\mathrm{NY}$ ), and plating using calibrated glass micropipettes. A $1 \mathrm{~mL}$ DI water sample placed into an unused Whirl-Pak bag was processed identically and acted as a control to assess the extent of possible contamination. A $1 \mathrm{mg}$ autoclaved soil sample was also utilized as a control. Colony counts were made after seven days using a colony counter (Bantex, Burlingame, CA) and were expressed in colony forming unit (CFU).

\section{Determination of soil fungus quality}

Fungi were isolated by subculturing hyphal tips (40/45x microscopy) from the advancing edge of each individual, isolated fungus colony; each hyphal tip was considered as an isolate. Two extra rounds of subculturing served to purify the fungus for identification. Each fungus was identified by obverse/reverse, microscopic spore, and phialide characteristics after about seven days (1000x under oil; Barnett \& Hunter 2003) and by comparison to pure cultures (University of Alberta Microfungus Collection and Herbarium, Toronto, ON; Agricultural Research Service Collection of Entomopathogenic Fungal Cultures, United States Department of Agriculture, Ithaca, NY; University of Cincinnati Microfungus Collection, University of Cincinnati, Cincinnati, OH). For purposes of spore production for identification, fungi were plated on PDA, Czapek Dox agar, cornmeal agar, and 2\% malt agar (Gams 1977, Kumpula et al. 2000, Barnett \& Hunter 2003, Watanabe 2010).

\section{Determination of fungus pathogenicity}

Unfed larvae of $D$. albipictus were obtained from 11 fed, mated females that had been collected from four calf moose (Alces alces) cadavers in accordance with collection permits (P. Pekins, University of New Hampshire, Durham, NH). Each fed female was placed into a meshcovered $50 \mathrm{~mL}$ polypropylene tube. Tubes were stored at $93 \% \mathrm{RH}\left(\mathrm{KNO}_{3}\right.$ solution; Winston \& Bates 1960) in a $2000 \mathrm{~mL}$ desiccator. Ticks were stored at $20^{\circ} \mathrm{C}, 10 \mathrm{~h} \mathrm{~L}: 14 \mathrm{~h} \mathrm{~L}: \mathrm{D}$ for oviposition and hatching. Larvae were handled and transferred using an aspirator. Twenty larvae were randomly selected from storage tubes, mounted on slides, and identified as D. albipictus based on characters in Lindquist et al. (2016). Larva could self-right and crawl five body lengths, as an indicator of good health. The life history of D. albipictus is about one year. Age of larvae used in the experiment was about five months, which approximates their questing age in the field (Samuel 2004). 
Standard methods, emphasizing Koch's postulates, were used to test pathogenicity of the fungus isolates to ticks (Tuininga et al. 2009, Suleiman et al. 2013, Cafarchia et al. 2015). An aqueous inoculum was prepared from a 1-month-old sporing plate culture of a fungus. Spores from the plate were scraped into phosphate buffered saline (PBS, pH 7.5) $+0.05 \%$ Tween 20 and adjusted to $1.3 \times 10^{8}$ spores/tick (AO Spencer Bright-Line hemocytometer, St. Louis, MO). Multiple spore inoculums of each test fungus were made so that ticks were not treated with spores from the same sporing culture. To treat larvae with fungus spores, the larvae, in groups of ten, were gently swirled in $1 \mathrm{~mL}$ spore inoculum for $2 \mathrm{~min}$, and then poured onto a piece of No. 3 Whatman filter paper (Whatman, Hillsboro, OR). After a few minutes of recovery, larvae that were observed crawling were collected and placed individually into a clean, mesh-covered $1.5 \mathrm{~mL}$ microcentrifuge tube. The control treatment was PBS + Tween. After treatment, the larvae were placed at $85 \% \mathrm{RH}$ (sat. KCl; Winston \& Bates 1960, 20 ${ }^{\circ} \mathrm{C}, 10 \mathrm{~h} \mathrm{~L}: 14 \mathrm{~h} \mathrm{D}$ ). After 10 days, the larvae were checked at 40x for their ability to self-right and crawl five body lengths. Larvae that showed lack of mobility, curled legs (legs I) and deflated opisthosoma were considered dead.

Dead larvae were subsequently rinsed for 1 min each in surface sterilizing solution (18:1:1 DI water: ethanol: $5.25 \% \mathrm{NaOCl}$ ), followed by two, fresh clean DI water rinses, and then sectioned with a scalpel. Each body portion was embedded in PDA and incubated at $20^{\circ} \mathrm{C}$ and darkness. Body portions were examined daily by 40/45x microscopy. Tips of hyphae that could be traced to having originated internally from with tick tissues within the body portion were subcultured and used for fungus identification. Internal fungus isolates were purified for identification (as described above), and they were compared to isolates that were used to prepare the inoculum that was used to treat the larvae as evidence of infection (Koch postulates).

\section{Data analysis}

From each bag of soil, three $1 \mathrm{~g}$ samples were taken, and each $1 \mathrm{~g}$ gram sample was analyzed by enumeration and fungus identification. Thus, each bag of soil was analyzed in triplicate and each $1 \mathrm{~g}$ sample was considered a replicate. The pathogenicity testing involved ten replicates of ten larvae each.

Data were expressed as the mean $\pm \mathrm{SE}$. An analysis of covariance (ANCOVA; $p=0.05$; JMP, SAS Institute, Cary, NC) was used to compare data in the treatment and control groups. Comparisons across samples were made using a reciprocal Simpson's (1949) diversity index, 1/D. Fungus quantities (CFU/g dry soil) were compared by a least significant difference (LSD) test. Mortality data were Abbott and log-it transformed prior to analysis (Tukey's).

Our rationale for providing all of the data from individual soil sampling sites is that individual records are important for examining abundance; 2. individual records provide more precision to give a better feel for distribution within the soil; 3. individual records allow for other investigators to use, analyze, and summarize these data in many more ways that an investigator could want; and 4. individual records could be important for future investigations, for example 10 years from now, in this part of Yukon.

\section{Results}

\section{Soil collection}

Soil sampling sites are shown in Table 1. Elk were observed year-round at sites 5-20. Elk are typically not observed at sites $1-4$. The $\mathrm{pH}$ of all 20 soil samples ranged $4.6 \pm 1.6$ to $6.0 \pm 1.3$, averaging $\mathrm{pH}$ of 5.3. For cataloging purposes, aliquots of these soil samples have been stored in 50 $\mathrm{mL}$ tubes at $4^{\circ} \mathrm{C}$ under sample lot YT1-20-X2018 and deposited at the Department of Biology, Wittenberg University, Springfield, OH, USA.

\section{Soil fungus quantity}

Majority ( $75 \%)$ of soil samples from sites where elk were observed had more fungi than sampling sites where elk were not observed: $10^{4-5} \mathrm{CFU} / \mathrm{g}$ dry soil compared to $10^{3-4} \mathrm{CFU} / \mathrm{g}$ dry soil, 
respectively, at $20^{\circ} \mathrm{C}$ (Table 1). In controls, only one plate out of a total of 60 showed evidence of contamination, a single Trichoderma sp. colony, when water rinses from unused Whirl-Pak soil collection bags and $1 \mathrm{mg}$ autoclaved soil samples ( $n=30$ plates each) were analyzed. Thus, our experimental manipulations and methods of soil collection did not appreciably impact the results.

In all cases, nearly identical results were obtained at $4^{\circ} \mathrm{C}$, as well as plating on SDA, except at $4^{\circ} \mathrm{C}$, growth was slower, and results took about twice as long to achieve than at $20^{\circ} \mathrm{C}$ (data not shown).

Table 1 Amount of fungi present in Yukon soils at the sampling sites. CFU, colony forming units. Sites 1-4, circled in red, are where elk are not observed. Data followed by same superscript letter within a column do not differ significantly $(p<0.05) .{ }^{*}$, denotes a significant difference $(p<0.05)$ between any non-elk and elk-present site. Image (PSS Adobe Systems, San Jose, CA): Dobrotka CJ. Data are the mean $\mathrm{CFU} \pm \mathrm{SE} \leq 1.7, n=3$ replicates of $1 \mathrm{~g}$ dry soil/site each.

\begin{tabular}{|c|c|c|c|c|}
\hline $\begin{array}{l}\text { Site \# } \\
\text { (cf. map) }\end{array}$ & $\begin{array}{l}\text { Elk observed } \\
\text { year around }\end{array}$ & $\begin{array}{l}\text { Fungi amount } \\
\text { (CFU/g dry soil) }\end{array}$ & $\begin{array}{l}\text { Map of Yukon, Canada } \\
\text { (Site \# labeled) }\end{array}$ & \\
\hline 1 & None & $1.4 \times 10^{4 a}$ & & \\
\hline 2 & None & $2.2 \times 10^{4 a}$ & & \\
\hline 3 & None & $1.6 \times 10^{3 \mathrm{~b}}$ & & \\
\hline 4 & None & $5.8 \times 10^{3 \mathrm{c}}$ & & \\
\hline 5 & Yes & $8.1 \times 10^{3 \mathrm{c}}$ & & \\
\hline 6 & Yes & $9.2 \times 10^{4 \mathrm{~d}^{*}}$ & & \\
\hline 7 & Yes & $4.8 \times 10^{4 \mathrm{e}^{*}}$ & & \\
\hline 8 & Yes & $7.4 \times 10^{4 \mathrm{f}^{*}}$ & & \\
\hline 9 & Yes & $1.1 \times 10^{5 \mathrm{~d}^{*}}$ & & \\
\hline 10 & Yes & $6.1 \times 10^{4 \mathrm{f}^{*}}$ & & \\
\hline 11 & Yes & $1.9 \times 10^{4 a}$ & & \\
\hline 12 & Yes & $3.5 \times 10^{4 \mathrm{e}^{*}}$ & & \\
\hline 13 & Yes & $7.1 \times 10^{3 \mathrm{c}}$ & & \\
\hline 14 & Yes & $3.9 \times 10^{4 \mathrm{e}^{*}}$ & & \\
\hline 15 & Yes & $5.1 \times 10^{4 \mathrm{e}^{*}}$ & & \\
\hline 16 & Yes & $3.3 \times 10^{4 \mathrm{e}^{*}}$ & & \\
\hline 17 & Yes & $4.6 \times 10^{4 \mathrm{e}^{*}}$ & & \\
\hline 18 & Yes & $9.2 \times 10^{3 \mathrm{c}}$ & & \\
\hline 19 & Yes & $8.0 \times 10^{4 f^{*}}$ & & \\
\hline 20 & Yes & $1.3 \times 10^{5 \mathrm{~g}^{*}}$ & & \\
\hline
\end{tabular}

\section{Soil fungus quality}

Twenty-nine fungi were isolated, representing 19 fungal genera, dominated by Penicillium and Mortierella (Tables 2-4). Acremonium, Cladosporium, Geomyces, Mortierella, Mucor, Penicillium, Phialophora, Phoma, and sterile fungi were isolated with regular frequency. Dark sterile fungi were isolated more frequently than hyaline sterile fungi. These data were pooled and grouped to permit comparison between elk inhabited and uninhabited sites (Fig. 1). The diversity of fungal components (reciprocal Simpson diversity index, 1/D $7.2 \pm 0.2$ versus $5.5 \pm 0.1 ; p<0.05$ ) in soils was greater in sampling sites where elk were present than where elk were not present.

Incubation at $4^{\circ} \mathrm{C}$ and $20^{\circ} \mathrm{C}$, as well as plating on PDA and SDA, yielded nearly identical results allowing extra time for results at $4^{\circ} \mathrm{C}$ (data not shown). Of the Mortierella/Penicillium fraction, the fungi isolated most frequently were $M$. elongata, secondarily $M$. alpina, and $P$. expansum.

\section{Fungus pathogenicity}

Approximately $2 / 3$ of the different soil fungus isolates caused significant mortality to unfed tick larvae in topical applications at $20^{\circ} \mathrm{C}$ (Table 5). Similar results were obtained at $4^{\circ} \mathrm{C}$ but took approximately six days longer (data not shown). Upon internal fungus culture, a high percentage of 
the fungus used as the treatment was recovered as having originated from within tissues of the larval cadavers. Aspergillus flavus, Beauveria, Beauveria bassiana, Paecilomyces, and Mucor were the most virulent, yielding $>\sim 70 \%$ mortality.

Of the large Mortierella/Penicillium fraction (Fig. 1), the dominant species, M. alpina yielded $49 \%$ mortality and $P$. expansum yielded $43 \%$ mortality, $4-5 x$ greater than mortality in the PBStreated controls. The $M$. elongata resulted in no significant mortality to larvae.

Table 2 Listing of fungi cultured from Yukon soil samples: no elk are observed at sites 1-4. Elk are observed year-round at sites 5-7. Plating on SDA yielded nearly identical results. $n=3$ replicates of $1 \mathrm{~g}$ dry soil/site each.

\begin{tabular}{llllllll}
\hline Fungus & \multicolumn{7}{c}{ \% mean \# isolates from soil sample at site 1 (Table 1): } \\
\cline { 2 - 8 } & 1 & 2 & 3 & 4 & 5 & 6 & 7 \\
\hline Composition ( \pm SE $\leq 2.6)$ & 0 & 9 & 0 & 0 & 0 & 0 & 0 \\
Acremonium spp. & 0 & 0 & 0 & 0 & 13 & 0 & 0 \\
Aspergillus nidulans & 0 & 0 & 0 & 0 & 0 & 11 & 0 \\
Beauveria bassiana & 0 & 0 & 0 & 0 & 0 & 11 & 0 \\
Botrytis spp. & 0 & 9 & 0 & 0 & 0 & 11 & 0 \\
Cladosporium spp. & 14 & 0 & 6 & 0 & 13 & 0 & 20 \\
Cladosporium cladosporioides & 0 & 9 & 6 & 0 & 0 & 22 & 0 \\
Geomyces pannorum & 7 & 9 & 0 & 17 & 0 & 0 & 20 \\
Mortierella spp. & 0 & 5 & 0 & 0 & 13 & 0 & 0 \\
Mortierella alpina & 14 & 9 & 0 & 17 & 25 & 0 & 40 \\
Mortierella elongata & 0 & 14 & 0 & 0 & 13 & 0 & 0 \\
Mucor spp. & 0 & 0 & 0 & 0 & 0 & 11 & 0 \\
Mycelia sterilia Hyaline & 7 & 5 & 0 & 0 & 0 & 0 & 0 \\
Mycelia sterilia Dark & 14 & 5 & 25 & 17 & 25 & 22 & 20 \\
Penicillium spp. & 0 & 5 & 13 & 0 & 0 & 0 & 0 \\
Penicillium chrysogenum & 21 & 18 & 13 & 0 & 0 & 0 & 0 \\
Penicillium expansum & 7 & 0 & 0 & 0 & 0 & 0 & 0 \\
Phoma spp. & 14 & 5 & 6 & 17 & 0 & 11 & 0 \\
Phialophora spp. & 0 & 0 & 19 & 33 & 0 & 0 & 0 \\
Trichoderma spp. & 0 & 0 & 13 & 0 & 0 & 0 & 0 \\
Trichoderma viride & 4.6 & 6.1 & 2.8 & 3.7 & 4.2 & 6.6 & 2.3 \\
\hline Simpson's index, 1/D & 0.2 & 0.1 & 0.1 & 0.2 & 0.2 & 0.1 & 0.1 \\
SE & & & & & &
\end{tabular}

Table 3 Listing of fungi cultured from Yukon soil samples: elk are observed year-round at these sites. Plating on SDA yielded nearly identical results. $n=3$ replicates of $1 \mathrm{~g}$ dry soil/site each.

\begin{tabular}{llllllll}
\hline Fungus & \multicolumn{7}{c}{ \% mean \# isolates from soil sample at site 1 (Table 1): } \\
\cline { 2 - 8 } & 8 & 9 & 10 & 11 & 12 & 13 & 14 \\
\hline Composition ( \pm SE $\leq 2.1)$ & 0 & 0 & 0 & 0 & 0 & 0 & 8 \\
Acremonium spp. & 0 & 9 & 0 & 0 & 0 & 14 & 0 \\
Aspergillus spp. & 0 & 0 & 0 & 0 & 3 & 0 & 5 \\
Aspergillus flavus & 0 & 0 & 0 & 5 & 3 & 0 & 0 \\
Aspergillus nidulans & 0 & 27 & 0 & 0 & 3 & 0 & 8 \\
Cladosporium spp. & 0 & 0 & 0 & 5 & 6 & 14 & 5 \\
Cladosporium cladosporioides & 0 & 9 & 0 & 0 & 0 & 14 & 3 \\
Fusarium spp. & 14 & 0 & 0 & 5 & 6 & 0 & 10 \\
Geomyces pannorum & 0 & 0 & 17 & 0 & 9 & 0 & 5 \\
Mortierella spp. & 0 & 9 & 0 & 5 & 0 & 0 & 0 \\
Mortierella alpina & 0 & 18 & 33 & 21 & 20 & 0 & 15 \\
Mortierella elongata & 0 & 0 & 0 & 5 & 11 & 0 & 0 \\
Mucor spp. & & & & & & & \\
\hline
\end{tabular}


Table 3 Continued.

\begin{tabular}{llllllll}
\hline Fungus & \multicolumn{7}{l}{ \% mean \# isolates from soil sample at site 1 (Table 1): } \\
\cline { 2 - 8 } & 8 & 9 & 10 & 11 & 12 & 13 & 14 \\
\hline Mycelia sterilia Dark & 0 & 0 & 0 & 5 & 0 & 0 & 0 \\
Paecilomyces spp. & 14 & 0 & 0 & 0 & 0 & 0 & 0 \\
Penicillium spp. & 29 & 18 & 0 & 21 & 20 & 29 & 21 \\
Penicillium chrysogenum & 0 & 0 & 33 & 0 & 6 & 0 & 0 \\
Penicillium expansum & 29 & 0 & 0 & 11 & 9 & 0 & 5 \\
Phoma spp. & 14 & 0 & 0 & 5 & 0 & 14 & 8 \\
Phialophora spp. & 0 & 9 & 17 & 11 & 6 & 14 & 3 \\
Rhizopus spp. & 0 & 0 & 0 & 0 & 0 & 0 & 5 \\
\hline Simpson's index, 1/D & 2.6 & 5.0 & 2.6 & 5.2 & 4.5 & 5.6 & 7.0 \\
SE & 0.1 & 0.2 & 0.2 & 0.1 & 0.1 & 0.1 & 0.2 \\
\hline
\end{tabular}

Table 4 Listing of fungi cultured from Yukon soil samples: elk are observed year-round at these sites. Plating on SDA yielded nearly identical results. $n=3$ replicates of $1 \mathrm{~g}$ dry soil/site each.

\begin{tabular}{lllllll}
\hline Fungus & \multicolumn{6}{l}{ \% mean \# isolates from soil sample at site 1 (Table 1): } \\
\cline { 2 - 8 } & 15 & 16 & 17 & 18 & 19 & 20 \\
\hline Composition ( \pm SE $\leq 2.5)$ & 0 & 0 & 0 & 10 & 0 & 0 \\
Alternaria spp. & 0 & 3 & 0 & 0 & 0 & 0 \\
Beauveria spp. & 0 & 0 & 0 & 0 & 0 & 8 \\
Beauveria bassiana & 0 & 0 & 0 & 10 & 0 & 0 \\
Botrytis spp. & 0 & 0 & 20 & 0 & 0 & 18 \\
Cladosporium spp. & 0 & 0 & 0 & 10 & 13 & 0 \\
Cladosporium cladosporioides & 0 & 6 & 0 & 0 & 13 & 0 \\
Epicoccum nigrum & 20 & 3 & 0 & 10 & 13 & 0 \\
Geomyces pannorum & 40 & 18 & 40 & 10 & 0 & 0 \\
Mortierella spp. & 0 & 3 & 0 & 0 & 13 & 8 \\
Mortierella alpina & 20 & 9 & 0 & 10 & 0 & 15 \\
Mortierella elongata & 0 & 12 & 0 & 0 & 0 & 15 \\
Mucor spp. & 0 & 3 & 0 & 0 & 0 & 0 \\
Mycelia sterilia Dark & 0 & 3 & 0 & 0 & 0 & 0 \\
Paecilomyces spp. & 20 & 18 & 0 & 0 & 25 & 23 \\
Penicillium spp. & 0 & 0 & 20 & 0 & 0 & 0 \\
Penicillium chrysogenum & 0 & 9 & 20 & 20 & 0 & 15 \\
Penicillium expansum & 0 & 3 & 0 & 10 & 0 & 0 \\
Phoma spp. & 0 & 6 & 0 & 10 & 25 & 8 \\
Phialophora spp. & 0 & 3 & 0 & 0 & 0 & 0 \\
Vertiriculum spp. & 2.3 & 4.7 & 2.8 & 7.6 & 5.6 & 4.3 \\
\hline Simpson’s index, 1/D & 0.2 & 0.1 & 0.1 & 0.1 & 0.2 & 0.2 \\
SE & & & & & &
\end{tabular}

Table 5 Subset of fungi isolated from Yukon soils that were pathogenic to unfed larvae of Dermacentor albipictus. PBS, phosphate buffered saline. -, not determined. Data (the mean \pm SE) followed by the same superscript letter within a column do not differ significantly $(p<0.05) ; n=$ 10 replicates of 10 ticks each.

\begin{tabular}{lll}
\hline & \multicolumn{2}{l}{ \% larvae 10 days post-treatment: } \\
\cline { 2 - 3 } $\begin{array}{l}\text { Treatment (topical application) } \\
\text { Controls }\end{array}$ & Dead & Positive for test fungus \\
\hline$\quad$ Untreated & $14 \pm 2.2^{\mathrm{a}}$ & - \\
PBS + Tween & $10 \pm 1.6^{\mathrm{a}}$ & - \\
\hline
\end{tabular}


Table 5 Continued.

\begin{tabular}{lll}
\hline Test Fungus & & \\
Acremonium sp. 2 & $22 \pm 1.8^{\mathrm{b}}$ & $68 \pm 2.2^{\mathrm{a}}$ \\
Alternaria sp. 2 & $46 \pm 2.2^{\mathrm{c}}$ & $83 \pm 1.4^{\mathrm{b}}$ \\
Aspergillus sp. 8 & $34 \pm 1.4^{\mathrm{d}}$ & $56 \pm 1.4^{\mathrm{c}}$ \\
Aspergillus flavus & $80 \pm 1.4^{\mathrm{e}}$ & $89 \pm 1.8^{\mathrm{b}}$ \\
Beauveria sp. 1 & $93 \pm 2.0^{\mathrm{e}}$ & $92 \pm 1.5^{\mathrm{a}}$ \\
Beauveria bassiana & $87 \pm 2.1^{\mathrm{e}}$ & $80 \pm 2.1^{\mathrm{b}}$ \\
Cladosporium cladosporioides & $33 \pm 1.7^{\mathrm{d}}$ & $64 \pm 1.7^{\mathrm{c}}$ \\
Epicoccum nigrum & $42 \pm 1.3^{\mathrm{c}}$ & $76 \pm 2.0^{\mathrm{b}}$ \\
Mortierella sp. 7 & $56 \pm 2.0^{\mathrm{f}}$ & $61 \pm 1.4^{\mathrm{c}}$ \\
Mortierella alpina & $49 \pm 1.4^{\mathrm{c}}$ & $71 \pm 1.7^{\mathrm{b}}$ \\
Mucor sp. 3 & $67 \pm 1.8^{\mathrm{g}}$ & $82 \pm 1.2^{\mathrm{b}}$ \\
Paecilomyces sp. 2 & $71 \pm 1.6^{\mathrm{g}}$ & $90 \pm 1.5^{\mathrm{a}}$ \\
Penicillium sp. 13 & $32 \pm 1.9^{\mathrm{d}}$ & $69 \pm 2.0^{\mathrm{b}}$ \\
Penicillium chrysogenum & $40 \pm 2.1^{\mathrm{c}}$ & $48 \pm 1.8^{\mathrm{d}}$ \\
Penicillium expansum & $43 \pm 2.1^{\mathrm{c}}$ & $56 \pm 1.3^{\mathrm{c}}$ \\
Trichoderma sp. 2 & $24 \pm 1.5^{\mathrm{b}}$ & $75 \pm 2.1^{\mathrm{b}}$ \\
Trichoderma viride & $62 \pm 1.4^{\mathrm{g}}$ & $77 \pm 1.8^{\mathrm{b}}$ \\
\hline
\end{tabular}
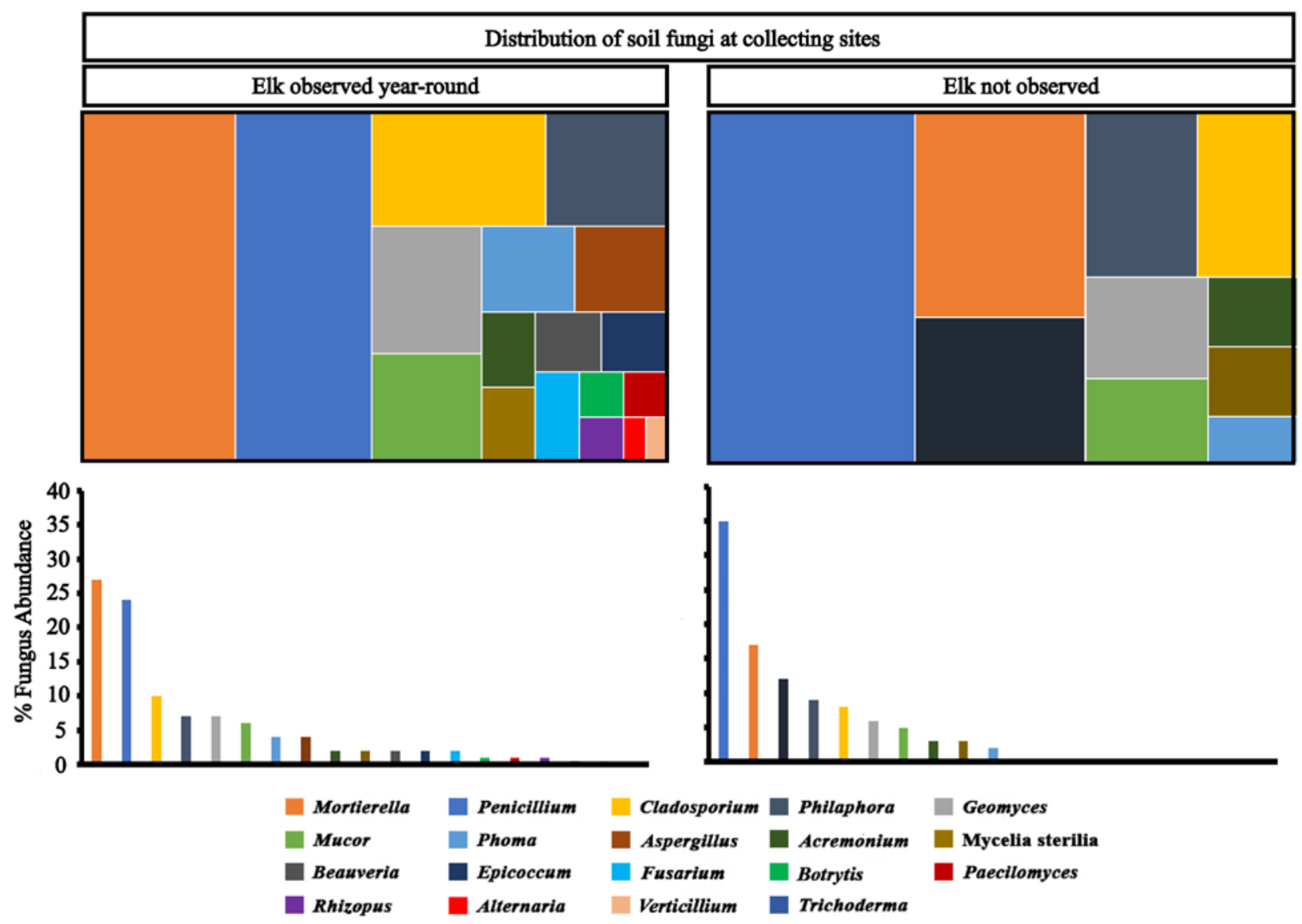

Fig. 1 - Distribution of soil fungi in Yukon soil samples (data from individual sampling sites combined; sites 5-20 on the right, and sites 1-4 on the left; Tables 2-4; sampling map in Table 1).

\section{Discussion}

This study demonstrates that Yukon soils consist of a multi-component mixture of several key groups of entomopathogenic fungi that cause significant mortality to unfed larvae of $D$. albipictus. A total of 29 soil fungi were identified, of which 17 of these produced mortalities of $>\sim$ 
$70 \%$, and most averaged $\sim 40 \%$ mortality to D. albipictus larvae by topical application of spores. The most virulent were Aspergillus flavus, Beauveria (mainly B. bassiana), Mucor, and Paecilomyces, each producing nearly complete larval mortality 10-day post-treatment with [ $10^{8}$ spores/tick], and these are well documented entomopathogenic fungi in tick biocontrol (Fernandes et al. 2012). Acremonium, Alternaria, various Aspergilli, Cladosporium cladosporioides, Epicoccum nigrum, Mortierella, various Penicillia, P. chrysogenum and P. expansum, and Trichoderma (usually reported as teleomorph Hypocrea), and T. viride are also common tick and mite entomopathogens (Bridge \& Worland 2009, Greengarten et al. 2011, Fernandes et al. 2012, Yoder et al. 2019) that were identified in Yukon soils. Some Antarctic isolates of M. alpina have been shown to be entomopathogenic to insects (Edgington et al. 2014), and we now extend this trend to include an entomopathogenic Yukon strain of M. alpina to ticks.

Our experiments examined the pathogenicity of these entomopathogenic soil fungus isolates alone, not in combination (common for this kind of investigation; Tuininga et al. 2009). We emphasize that in natural soil habitat, the tick larva would be exposed to a mixture of spores from these fungi, the composition of which varies seasonally depending upon weather and soil condition (Greengarten et al. 2011, Timling \& Taylor 2012). None of the fungus isolates that we found that display entomopathogenic activity from Yukon soils are unusual for ticks, and neither is the isolation of these tick entomopathogenic fungi from soil (Tuininga et al. 2009, Greengarten et al. 2011, Yoder et al. 2018). Origin from Yukon, isolation at both $4^{\circ} \mathrm{C}$ and $20^{\circ} \mathrm{C}$ (criteria in Bergero et al. 1999, Kurek et al. 2007), and pathogenicity at both $4^{\circ} \mathrm{C}$ and $20^{\circ} \mathrm{C}$ suggest that these soil fungi are psychrotrophic strains of regular entomopathogenic fungi that work against $D$. albipictus larvae.

From a classical biological control perspective, these Yukon-native, entomopathogenic fungus strains would appear ideal for population management of D. albipictus in more northern, polar climates. These entomopathogenic fungus isolates have not yet been tested in the field in locales where $D$. albipictus are abundant. We are encouraged by results of other studies showing reduced number of ticks in field application with entomopathogenic fungi (Benjamin et al. 2002, Kirkland et al. 2004, Greengarten et al. 2011, Fernandes et al. 2012). Nearly the same set of entomopathogenic fungi that we report here for $D$. albipictus have been reported by Greengarten et al. (2011) to be pathogenic to the black-legged tick Ixodes scapularis, thus suggesting an overlap between the soil fungus components that are entomopathogenic to both of these tick species. I. scapularis is one of the most important medical-veterinary ticks. It seems reasonable to suggest that these Yukon-native entomopathogenic fungus strains could be used effectively for biological control of I. scapularis. This would have public health significance considering reports that $I$. scapularis has been observed in Yukon as well as Alaska (Scott 2016, Durden et al. 2016).

Our soil sampling occurred in October, coincident with autumn D. albipictus larvae questing season and elk breeding season. These Yukon soil samples display a typical mycoflora profile characteristic of subarctic, Arctic soils, and acidified forested habitats, with all of these fungi known to be psychrotrophs and regular agents of saprobic decay (Bergero et al. 1999, Kumpula et al. 2000, Robinson 2001, Kurek et al. 2007, Singh et al. 2012, Ali et al. 2013). For Yukon soil samples, Mortierella, Penicillium, Phialophora, Cladosporium, Geomyces, Mucor and dark sterile fungi were isolated most frequently, with Mortierella and Penicillium predominating ( $\sim 1 / 2$ of total culturable soil mycoflora). Mortierella alpina and $P$. expansum were the dominant species within this large Mortierella/Penicillium fraction, thus indicating that both of these entomopathogenic fungi to $D$. albipictus larvae prevail in high frequency in Yukon soils. The entomopathogenic fungus $C$. cladosporioides was the main species within the Cladosporium fraction of Yukon soils, which is another entomopathogenic fungal species that prevails at high frequency.

Results here are from an October sampling, based on when D. albipictus larvae would be out and biting. It is unlikely that this mycoflora profile is rigidly fixed. Shifts in fungal composition occur in response to seasonal fluctuations in temperature, weather, and animal activity (Carreiro \& Koske 1992, Robinson 2001, Timling \& Taylor 2012). Amounts of fungi, and diversity of components, tend to be higher in regions that are occupied by animals, as a product of nutrient enrichment to the soil and animal behavioral activity (Kumpula et al. 2000, Ali et al. 2013). 
Warmer soil microclimate is likely another important factor (Carreiro \& Koske 1992), in that regions elk occupy lose snow early, and the dark soil is heated all summer by the spring summer 24h sun. In contrast, the mycoflora profile of soil from sites where elk are not observed is less diverse and dominated by Mortierella. Our results conform to this reasoning: the lower diversity of fungi in sites where elk are not observed (i.e., cold, and snow covered longer) is a product of low temperature selecting for Zygomycetes (like psychrotrophic Mortierella) and selecting against mesophiles (Mitosporic Fungi, for instance Penicillium) as described for fungi in forested soils by Carreiro \& Koske (1992).

It was not surprising that we generally found that areas where elk were observed year-round were characterized by higher amounts (CFU/g dry soil) and greater diversity (1/D) of soil fungi, many that are entomopathogenic. Increasing spore concentration, and differences in mode of action of entomopathogenic fungi increase the tick's risk of exposure and infection (Fernandes et al. 2012). Thus, whether increased amount and diversity of entomopathogenic fungi, and whether the growth of entomopathogenic fungi peak in October, translate into enhanced control and management of $D$. albipictus in areas that elk occupy seem feasible but remains to be examined.

Taken together, soil fungi are an important natural regulator that could offer some degree of protection, managing, slowing, or preventing the spread and establishment of $D$. albipictus. The entomopathogenic soil fungi identified here, by increasing quantity and diversity of kinds of fungi that are bioactive, appear to be important for managing D. albipictus levels in elk at the populationand individual animal-level in Yukon. Presence of elk generates entomopathogenic fungi that help to reduce the abundance of $D$. albipictus larvae (infestation stage) in regions that the elk (ticks) occupy; this is likely a product of warmer soil microclimate, animal presence, nutrient enrichment, and/or some other (unidentified) climatic factor.

Isolation of these entomopathogenic soil fungi, local Yukon isolates, increases possibility for biological control of $D$. albipictus in low-temperature environments, and we hope that these fungi will be important for making better informed decisions about $D$. albipictus management. Fernandes et al. (2012) is a useful guide for this purpose. Whether any of these entomopathogenic fungi (Yukon strains) that we isolated here will be useful for commercial applications as tick control agents in classical biological control programs is not known, but these entomopathogenic fungi are definitely a part of the natural regulatory potential.

\section{Acknowledgements}

Funded by a gift from Elizabeth E. Powelson to the Department of Biology for support of undergraduate research at Wittenberg University.

\section{References}

Ali SH, Alias SA, Siang HY, Smykla J, Pang, K-L, Guo S-Y, Convey P. 2013 - Studies on diversity of soil microfungi in the Hornsund area, Spitsbergen. Polish Polar Research 34, 3954.

Barnett JL, Hunter BB. 2003 - Illustrated Genera of Imperfect Fungi. American Phytopathological Society Press, St. Paul, MN.

Benjamin MA, Zhioua E, Ostfeld RS. 2002 - Laboratory and field evaluation of the entomopathogenic fungus Metarhizium anisopliae (Deuteromycetes) for controlling questing adult Ixodes scapularis (Acari: Ixodidae). Journal of Medical Entomology 39, 723-728.

Bergero R, Girlanda M, Varese GC, Intili D, Luppi AM. 1999 - Psychrooligotrophic fungi from Arctic soils of Franz Joseph Land. Polar Biology 21, 361-368.

Bridge PD, Worland MR. 2009 - An association between the Antarctic mite Alaskozetes antarcticus and an entomophthoralean fungus of the genus Neozygites. In: Bruin J, van der Geest LPS (eds), Diseases of Mites and Ticks. Springer, New York. pp. 43-52.

Cafarchia C, Immediato D, Iatta R, Ramos RAN et al. 2015 - Native strains of Beauveria bassiana for the control of Rhipicephalus sanguineus sensu lato. Parasites \& Vectors 8, 80. 
doi: 10.1186/s13071-015-0693-9.

Carreiro MM, Koske RE. 1992 - Room temperature isolations can bias against selection of low temperature microfungi in temperate forest soils. Mycologia 84, 886-900.

Durden LA, Beckmen KB, Gerlach RF. 2016 - New records of ticks (Acari: Ixodidae) from dogs, cats, humans, and some wild vertebrates in Alaska: invasion potential. Journal of Medical Entomology 53, 1391-1395.

Edgington S, Thompson E, Moore D, Hughes KA, Bridge P. 2014. - Investigating the insecticidal potential of Geomyces (Myxtrhichaceae: Helotiales) and Mortierella (Mortierellacea: Mortierellales) isolated from Antarctica. Springerplus 3, 289. doi: 10.1186/2193-1801-3-289.

Fernandes EKKK, Bittencourt VREP, Roberts DW. 2012 - Perspectives on the potential of entomopathogenic fungi in biological control of ticks. Experimental Parasitology 130, 300305.

Gams W. 1977 - A key to the species of Mortierella. Persoonia 9, 381-391.

Greengarten PJ, Tuininga AR, Morath SU, Falco RC et al. 2011 - Occurrence of soil- and tickborne fungi and related virulence tests for pathogenicity to Ixodes scapularis (Acari: Ixodidae). Journal of Medical Entomology 48, 337-344.

Holmes CJ, Dobrotka CJ, Farrow DW, Rosendale AJ et al. 2018 - Low and high thermal tolerance characteristics for unfed larvae of the winter tick Dermacentor albipictus (Acari: Ixodidae) with special reference to moose. Ticks and Tick-borne Diseases 9, 25-30.

Kalra Y. 1995 - Determination of pH of soils by different methods: collaborative study. Journal of AOAC International 78, 310-324.

Kirkland BH, Westwood GS, Keyhani NO. 2004 - Pathogenicity of entomopathogenic fungi Beauveria bassiana and Metarhizium anisopliae to Ixodidae tick species Dermacentor variabilis, Rhipicephalus sanguineus and Ixodes scapularis. Journal of Medical Entomology 41, 705-711.

Kumpula J, Parikka R, Nieminen M. 2000 - Occurrence of certain microfungi on reindeer pastures in northern Finland during winter 1996-97. Rangifer 20, 3-8.

Kurek E, Korniłłowicz-Kowalska T, Słomka A, Melke J. 2007 - Characteristics of soil filamentous fungi communities isolated from various mico-relief forms in the high Arctic tundra (Bellsund region, Spitsbergen). Polish Polar Research 28, 57-73.

Leo SST, Samuel WM, Pybus MJ, Sperling FAH. 2014 - Origin of Dermacentor albipictus (Acari: Ixodidae) on elk in the Yukon, Canada. Journal of Wildlife Diseases 50, 544-551.

Lindquist EE, Galloway TD, Artsob H, Lindsay LR et al. 2016 - A Handbook to the Ticks of Canada (Ixodida: Ixodidae, Argasidae). Vol 7. Biological Survey of Canada Monograph Series, Charlottetown, PE.

Robinson CH. 2001 - Cold adaptation in Arctic and Antarctic fungi. New Phytologist 151, 341353.

Samuel B. 2004 - White as a Ghost: Winter Ticks and Moose. Vol. 1. Federation of Alberta Naturalists, Edmonton, Alberta.

Scott JD. 2016 - Studies abound on how far north Ixodes scapularis ticks are transported by birds. Ticks and Tick-borne Diseases 7, 327-328.

Simpson EH. 1949 - Measurement of diversity. Nature 163, 688.

Singh SM, Kingh SK, Yadav LS, Singh PN, Ravindra R. 2012 - Filamentous soil fungi from NyÅlesund, Spitsbergen, and screening for extracellular enzymes. Arctic 65, 45-55.

Suleiman EA, Shigidi MT, Hussan SM. 2013 - Activity of Scopulariopsis brevicaulis on Hyalomma anatolicum and Amblyomma lepidum (Acari: Ixodidae). International Journal of Medical Sciences 13, 667-675.

Timling I, Taylor DL. 2012 - Peeking through a frosty window: molecular insights into the ecology of Arctic soil fungi. Fungal Ecology 5, 419-429.

Tuininga AR, Miller JL, Morath SU, Daniels TJ et al. 2009 - Isolation of entomopathogenic fungi from soils and Ixodes scapularis (Acari: Ixodidae) ticks: prevalence and methods. Journal of Medical Entomology 46, 557-565. 
Watanabe T. 2010 - Pictorial Atlas of Soil and Seed Fungi: Morphologies of Cultured Fungi and Key to Species. $3^{\text {rd }}$ ed. CRC Press, New York, NY.

Winston PW, Bates DS. 1960 - Saturated solutions for the control of humidity in biological research. Ecology 41, 232-237.

Yoder JA, Dobrotka CJ, Fisher KA, LeBarge AP et al. 2018 - Entomopathogenic fungi of the winter tick in moose wallows: A possible bio-control for adult moose? Alces 54, 1-16.

Yoder JA, Pekins PJ, Dobrotka CJ, Fisher KA et al. 2019 - Enhancement of fur and skin from bull moose with additional entomopathogenic fungi that offer increased protection against damage from winter ticks (Dermacentor albipictus; Acari: Ixodidae). International Journal of Acarology doi: 10.1080/01647954.2018.1554700.

Yoder JA, Pekins PJ, Nelson BW, Randazzo CR, Siemon BP. 2017 - Susceptibility of winter tick larvae and eggs to entomopathogenic fungi- Beauveria bassiana, Beauveria caledonica, Metarhizium anisopliae, and Scopulariopsis brevicaulis. Alces 53, 41-51.

Zarnke RL, Samuel WM, Franzmann AW, Barrett R. 1990 - Factors influencing the potential establishment of the winter tick (Dermacentor albipictus) in Alaska. Journal of Wildlife Diseases 26, 412-415. 